\title{
Neuronal Correlates of Brain-derived Neurotrophic Factor Val66Met Polymorphism and Morphometric Abnormalities in Bipolar Disorder
}

\author{
Koji Matsuo' ${ }^{1,2}$, Consuelo Walss-Bass', Fabiano G Nery ${ }^{1,3}$, Mark A Nicoletti ${ }^{4,5}$, John P Hatch ${ }^{1,6}$, \\ Benicio N Frey ${ }^{7}$, Emel S Monkul ${ }^{1,3}$, Giovana B Zunta-Soares', Charles L Bowden', Michael A Escamilla',8 and \\ Jair C Soares*,4,5 \\ 'Department of Psychiatry, The University of Texas Health Science Center, San Antonio, TX, USA; ${ }^{2}$ Division of Neuropsychiatry, Department of \\ Neuroscience, Yamaguchi University Graduate School of Medicine, Yamaguchi, Japan; ${ }^{3}$ Bipolar Disorder Research Program (PROMAN), Institute \\ of Psychiatry, Department of Psychiatry, University of Sao Paulo Medical School, Sao Paulo, Brazil; " Department of Psychiatry, University of North \\ Carolina, Chapel Hill, NC, USA; ${ }^{5}$ Center of Excellence for Research and Treatment of Bipolar Disorder (CERT-BD), University of North Carolina, \\ Chapel Hill, NC, USA; ${ }^{6}$ Department of Orthodontics, The University of Texas Health Science Center, San Antonio, TX, USA; ${ }^{7}$ Department of \\ Psychiatry and Behavioural Neurosciences, McMaster University, Hamilton, Canada; ${ }^{8}$ Department of Cellular and Structural Biology, University of \\ Texas Health Science Center, San Antonio, TX, USA
}

\begin{abstract}
The brain-derived neurotrophic factor (BDNF) Val66Met polymorphism has been proposed as a possible candidate for involvement in the pathophysiology of bipolar disorder (BD). To determine whether an association exists between the BDNF Val66Met genotype and morphometric abnormalities of the brain regions involved in memory and learning in BD and healthy subjects. Forty-two BD patients and 42 healthy subjects were studied. Interactions between BDNF Val66Met genotype and diagnosis in gray (GM) volumes were analyzed using an optimized voxel-based morphometry technique. Declarative memory function was assessed with the California Verbal Learning Test II. Left and right anterior cingulate GM volumes showed a significant interaction between genotype and diagnosis such that anterior cingulate GM volumes were significantly smaller in the Val/Met BD patients compared with the Val/Val BD patients (left $P=0.01$, right $P=0.01$ ). Within-group comparisons revealed that the Val/Met carriers showed smaller GM volumes of the dorsolateral prefrontal cortex compared with the $\mathrm{Val} / \mathrm{Val}$ subjects within the BD patient $(P=0.0 \mathrm{I})$ and healthy groups (left $P=0.03$, right $P=0.03$ ). The $\mathrm{Val} /$ Met healthy subjects had smaller GM volumes of the left hippocampus compared with the $V$ al/ $\mathrm{Val}$ healthy subjects $(P<0.0 \mathrm{I})$. There was a significant main effect of diagnosis on memory function $(P=0.04)$, but no interaction between diagnosis and genotype was found $(P=0.48)$. The findings support an association between the BDNF Val66Met genotype and differential gray matter content in brain structures, and suggest that the variation in this gene may play a more prominent role in brain structure differences in subjects affected with BD.
\end{abstract}

Neuropsychopharmacology (2009) 34, 1904-19|3; doi:I0.1038/npp.2009.23; published online I8 March 2009

Keywords: bipolar disorder; BDNF; cingulate cortex; voxel-based morphometry; memory; gray matter

\section{INTRODUCTION}

Components of the limbic-thalamic-cortical and the limbic-striatal-pallidal-thalamic-cortical networks participate in mood regulation, cognitive processes, and behavior

These findings were presented in part at the annual meeting of the Society of Biological Psychiatry, 17-19 May 2007, San Diego, CA, USA * Correspondence: JC Soares, Department of Psychiatry, Center of Excellence for Research and Treatment of Bipolar Disorder (CERTBD), Campus Box 7160, University of North Carolina, Chapel Hill, NC 27599-7I60, USA, Tel: 919966 8832, Fax: 9199667659 ,

E-mail: jsoares@med.unc.edu

Received 2 June 2008; revised 19 December 2008; accepted 9 January 2009 regulation. Specific abnormalities of the hippocampus, amygdala, and the cingulate, and prefrontal cortices have been reported in patients with mood disorders, and these regions have been implicated in the pathophysiology of mood disorders (Soares and Mann, 1997). The brain abnormalities in patients with bipolar disorder (BD) could potentially result from genetic factors, which regulate brain development or neurodegeneration. However, there is little information on the influence of specific genetic factors on these brain abnormalities.

The brain-derived neurotrophic factor (BDNF) polymorphism gene (Val66Met) has been proposed as a candidate for possible involvement in the abnormal mood regulation that characterizes mood disorders (Neves-Pereira 
et al, 2002; Sklar et al, 2002). BDNF is highly expressed in the cortex, hippocampus, limbic structures, cerebellum, and the olfactory bulb (Huang and Reichardt, 2001; Vigers et al, 2000; Yan et al, 1997), where it is involved in basic neuronal functions, such as cell survival, axonal outgrowth, dendritic growth, and synaptic plasticity. Animal studies also support the association between BDNF and several treatments for mood disorders, including antidepressants, lithium, valproate, electroconvulsive therapy, and repetitive transcranial magnetic stimulation. All of these interventions influence the expression of BDNF messenger RNA or BDNF protein in the hippocampus and frontal lobe (Muller et al, 2000; Nibuya et al, 1995; Russo-Neustadt et al, 1999). In humans, a postmortem study showed that subjects with mood disorders who were taking antidepressants at the time of death had increased BDNF immunoreactivity in hippocampal tissue compared with unmedicated patients (Chen et al, 2001). Family-based association studies show that the Val66Met polymorphism is associated with the diagnosis of $\mathrm{BD}$ and the phenomenon of rapid cycling (Green et al, 2006; Lohoff et al, 2005) and early age of illness onset (Tang et al, 2008) in BD patients, albeit some other studies did not show this association (Gratacos et al, 2007; Kanazawa et al, 2007; Kunugi et al, 2004). Moreover, both BD and major depressive disorder (MDD) patients show decreased serum levels of BDNF (Cunha et al, 2006; Karege et al, 2004; Machado-Vieira et al, 2007) compared to healthy subjects, and there is an inverse correlation between BDNF levels and severity of the depressive (Karege et al, 2004; MachadoVieira et al, 2007; Shimizu et al, 2003) and manic states (Cunha et al, 2006). A magnetic resonance study demonstrated that serum BDNF levels are positively associated with the concentration of $\mathrm{N}$-acetyl aspartate, a marker of neuronal integrity, and choline, a marker of cell membrane turnover, in the anterior cingulate cortex (ACC) (Lang et al, 2007), suggesting that peripheral BDNF content may be a potential marker of cerebral cortical integrity.

A human BDNF polymorphism gene, leading to a valine or methionine substitution at position 66 in the prodomain (Val/Met), plays a crucial role in memory formation. Healthy subjects with Val/Met BDNF also receive lower scores on cognitive tasks compared with $\mathrm{Val} / \mathrm{Val}$ subjects (Egan et al, 2003; Hariri et al, 2003). In neuroimaging studies, healthy Val/Met subjects show smaller hippocampal (Bueller et al, 2006; Pezawas et al, 2004), parahippocampal (Nemoto et al, 2006) and dorsolateral prefrontal cortex (DLPFC) (Pezawas et al, 2004) volumes compared with Val/ Val subjects. Psychiatric patients show associations between the BDNF Val66Met polymorphism and brain abnormalities in schizophrenia (Egan et al, 2003; Ho et al, 2006; Szeszko et al, 2005) and MDD (Frodl et al, 2007). Among BD patients, Met carriers showed greater volume loss within the temporal lobe over 4 years compared with $\mathrm{Val} / \mathrm{Val}$ patients (McIntosh et al, 2007). We demonstrated that the Val66Met polymorphism affects creatine + phosphocreatine levels in the DLPFC of BD patients (Frey et al, 2007b). More specifically, Met carriers had lower creatine + phosphocreatine levels, which suggests impaired energy metabolism in the DLPFC of BD.

Despite the mounting evidence for BDNF abnormalities in $\mathrm{BD}$, to our knowledge, the association between the Val66Met polymorphism, cerebral gray matter and memory in $\mathrm{BD}$ has not been investigated. The objective of this study was to examine the association between the BDNF Val66Met polymorphism and morphometric brain abnormalities in BD patients. We hypothesized that Met carrier subjects (Val/Met and Met/Met) would have smaller volumes of the hippocampus, ACC and DLPFC that contribute to memory and cognitive function compared with $\mathrm{Val} / \mathrm{Val}$ homozygotes. We further hypothesized that the brain volume differences between Val/Val homozygotes and Met carriers would be larger among subjects with $\mathrm{BD}$ than among healthy comparison subjects.

\section{METHODS}

\section{Subjects}

Forty-two patients with $\mathrm{BD}$ and 42 healthy subjects were studied. This study was approved by the Institutional Review Board of The University of Texas Health Science Center at San Antonio. Written informed consent was obtained from all the participants after a complete description of the study was provided. The participants were recruited at hospitals and clinics and through advertisement broadcast in the community. All of the patients met DSM-IV-TR criteria for BD by the Structured Clinical Interview (SCID) for DSM-IV (First et al, 1996b). Healthy subjects were screened for DSM-IV axis I disorders by the SCID non-patient version (First et al, 1996a). Patients who had a history of electroconvulsive therapy or a substance use disorder within 6 months preceding the study were excluded. Healthy control subjects who had current or past axis I DSM-IV psychiatric disorders or had first-degree relatives with any Axis I psychiatric disorder were excluded. All participants were evaluated for handedness by the Edinburgh inventory (Oldfield, 1971). All participants also received laboratory tests and a physical examination to rule out physical illnesses. Any participant with current endocrinological disease, history of head trauma with loss of consciousness, current or previous neurological disease, family history of hereditary neurological disorders, or a current medical condition such as active liver disease, kidney problems, or respiratory problems was excluded. A senior psychiatrist (JCS) reviewed all clinical information and medical or neurological conditions and confirmed DSM-IV diagnostic criteria. Current mood states of the patients were evaluated using the 21-item Hamilton Rating Scale for Depression (HAM-D) (Hamilton, 1960) and the Young Mania Rating Scale (YMRS) (Young et al, 1978). Verbal and non-verbal general intellectual abilities were assessed using the Wechsler Test of Adult Reading (WTAR) (Holnack, 2001) and the Test of Non-verbal Intelligence-3 (TONI-3)(Brown et al, 1997).

\section{MRI Acquisition}

Brain images were collected on a Philips 1.5 T MR system (Philips Medical System, Andover, MA). Images were collected by means of an axial 3-dimensional T1-weighted field fast echo sequence (field of view $256 \mathrm{~mm}$, view matrix $256 \times 256$, repetition time $24 \mathrm{~ms}$, echo time $5 \mathrm{~ms}$, flip angle $40^{\circ}$, slice thickness $1 \mathrm{~mm}$ ). 
Image analysis. Preprocessing was performed using SPM2 software (Wellcome Department of Imaging Neuroscience, London, United Kingdom) running under Matlab 7.1.0 (MathWorks, Natick, MA). The images were preprocessed following the optimized voxel-based morphometry (VBM) protocol (Good et al, 2001). First, we created a customized anatomical T1 template and prior probability images from the sample of all 84 participants. All original images were manually aligned on the anterior commissure-posterior commissure line. The customized T1 template was created by averaging the images of all the participants and prior probability images by an optimized VBM script (http://dbm.neuro.uni-jena.de/vbm/). The original images were analyzed using this own template. The extracted segmented images were normalized with the own gray matter (GM) template. Deformation parameters were applied to the original images followed by a second segmentation step in stereotactic space. This procedure automatically removed non-brain tissues including scalp tissue, skull and dural venous sinus. Finally, the segmented images were modulated by Jacobian determinants derived from the spatial normalization. Images were obtained in $1 \times 1 \times 1 \mathrm{~mm}$ resolution by the optimized VBM script. These images were smoothed with an $8 \mathrm{~mm}$ Gaussian filter.

\section{Genotyping Procedure}

Blood samples were collected from all subjects and identified by codes, and DNA was subsequently extracted. BDNF Val66Met genotype was determined using the Taqman 5', with a Peltier Thermal Cycler and the ABI (Applied Biosystems, Foster City, CA) 7900 Sequence Detection System. The $5^{\prime}$ nuclease assay was used, which allows direct detection of the polymerase chain reaction product by the release of a fluorescent reporter. We used two fluorescent probes, one for each single nucleotide polymorphism allele, that hybridize to the target sequence in the assay. Each probe consists of an oligonucleotide with a $5^{\prime}$-reporter fluorescent dye (either 6-carboxy-fluorescine or $\mathrm{VIC}^{\mathrm{TM}}$ ) and a $3^{\prime}$ non-fluorescent quencher. Genotyping error rate for this assay was determined by replicate genotyping of sample, and was $<0.005$. The genotyping was performed with the clinical status of the subjects masked, and genotypes were scored using the SDS2.1 software program from ABI. When the probe is intact, the proximity of the reporter and quencher results in the suppression of fluorescence. As the Taq polymerase cleaves the probe with its $5^{\prime}$ to $3^{\prime}$ nuclease activity, the reporter dye is separated from the quencher, resulting in increased fluorescence. The fluorescence intensity was read and quantified by the ABI Prism $7900 \mathrm{HT}$, allowing for immediate availability of the genotype information. Primers and probes for each single nucleotide polymorphism were obtained using the custom assay-by-demand service offered by ABI. Eighteen randomly selected short tandem repeat markers (DXS993, D9S285, D4S392, D21S252, D20S117, D19S571, D16S515, D14S276, D10S1653, D11S904, D7S510, D7S507, D6S422, D5S641, D3S1569, D2S396, D2S168, and D12S368) were genotyped as control markers to test for possible stratification effects.

\section{Neuropsychological Testing}

We administered the California Verbal Learning Test II (CVLT-II)(Delis et al, 2000) to evaluate verbal learning and recall declarative memory. Subjects listened to a list of 16 items belonging to four categories presented at a rate of one item per second and were then requested to repeat as many as they can remember. This procedure was repeated in five trials and the score for each trial was recorded. The total score (CVLT-II total) is the sum of the five trials. An interference trial with a different list of 16 items is then performed, and the subjects are asked to recall this new list. This test is followed by subjects being asked to recall the items in the initial list (CVLT-II short delay free) and then again after they are provided with the categories as cues (CVLT-II short delay cued). After $20 \mathrm{~min}$ of performing a distracter task, the subjects are asked to recall the initial items spontaneously (CVLT-II long delay free) and again after being provided with the categories as cues (CVLT-II long delay cued).

\section{Statistical Analysis}

For image analysis, we used SPM2 software that implemented a General Linear Model. We selected three a priori regions of interest (ROIs) based on previous neuroimaging studies: DLPFC, ACC, and hippocampus. We identified these regions using Talairach Daemon (Lancaster et al, 2000) and automated anatomical labeling (Tzourio-Mazoyer et al, 2002) through WFU PickAtlas version 2 (Maldjian et al, 2004; Maldjian et al, 2003). Total brain volumes were calculated by the optimized VBM script. Age, sex (Good et al, 2001; Sowell et al, 2003) and total brain volumes were treated as nuisance variables in SPM2. We analyzed the interaction between genotype and diagnosis. Within-group comparisons were also done in SPM2 to test the difference between the ROI volumes of the $\mathrm{Val} / \mathrm{Val}$ and Met carriers in the healthy and $\mathrm{BD}$ subject groups. The resulting set voxel values for each contrast constituted an SPM $t$ statistic (SPM $\{t\})$. Significant results were reported at $P<0.05$ corrected for multiple comparisons at both cluster and voxel levels. At the voxel level, we applied the small volume False Discovery Rate correction in SPM and extent threshold $=50$ voxels to confirm our hypothesis. All results are presented as Talairach coordinates, which we obtained by applying Brett's transformation (www.mrc-cbu.cam.ac.uk/Imaging/Common/ mnispace.shtml) to the MNI coordinates output by SPM2.

In genotyping, the allele frequencies and genotype distribution of BDNF were compared with Hardy-Weinberg equilibrium. Fisher's exact test was applied to compare the Val66Met genotypes with regard to the control markers.

The CVLT data were analyzed using ANOVA for repeated measures with one within subjects factor with seven levels ( $t 1$ to $\mathrm{t} 5$, short recall and long delay recall) and two between subjects factors each with two levels (diagnosis, ie, BD patients $v s$ healthy comparison subjects, and genotype, ie, $\mathrm{Val} / \mathrm{Val}$ vs Met carrier) using SPSS software (SPSS Inc., Chicago, IL).

\section{RESULTS}

\section{Demographic and Clinical Data}

The genotype distribution was 24 (57\%) Val/Val and 18 (43\%) $\mathrm{Val} / \mathrm{Met}$ subjects in the BD group and $29(69 \%)$ 
Val/Val and 13 (31\%) Val/Met subjects among the healthy subjects. The distribution was not significantly different between the two groups $(P=0.37)$. No subject with the Met/Met allele participated in the study. One control marker (D3S1569), out of 18 tested, was unequally distributed between the $\mathrm{Val} / \mathrm{Val}$ and $\mathrm{Val} / \mathrm{Met}$ subjects $(P=0.04)$, which is similar to what one would expect to find by chance for this number of markers. The remaining 17 control markers were equally distributed between $\mathrm{Val} / \mathrm{Val}$ and $\mathrm{Val} / \mathrm{Met}$ subjects $(P s>0.1)$. There was no significant difference between $\mathrm{Val} / \mathrm{Val}$ and $\mathrm{Val} / \mathrm{Met}$ subjects with regard to the distributions of sex, age, years of education, verbal IQ, nonverbal IQ, or handedness $(P s>0.05)$ (Table 1). For the BD patients, the mean age of onset of illness was $16.6 \pm 6.7$ years (mean $\pm \mathrm{SD}$ ), and the mean length of illness was $18.3 \pm 11.0$ years. The mean number of episodes was $26.4 \pm 25.7$ for 18 of the patients; the number of episodes was 'too numerous to count' in the remaining 24 patients. The mean HAM-D score was $14.5 \pm 8.9$, and the mean YMRS score was $7.9 \pm 6.7$ years. Twelve patients were depressed, four were manic, four were mixed, and 22 were euthymic. Thirteen patients were unmedicated and 29 were taking psychiatric medications including mood stabilizers $(n=22)$, antidepressants $(n=21)$ and atypical antipsychotropics $(n=12)$ at the time of the study. Thirty-four patients were diagnosed as having bipolar I disorder, and eight patients had bipolar II disorder. Twenty-two patients had one or more comorbid anxiety disorders including panic disorder $(n=5)$, generalized anxiety disorder $(n=7)$, post traumatic stress disorder $(n=4)$, obsessive-convulsive disorder $(n=4)$, and specific phobia $(n=7)$. No patients met the diagnostic criteria for substance abuse or dependence disorder within 6 months preceding the study. There was no statistical difference between $\mathrm{Val} / \mathrm{Met}$ and $\mathrm{Val} / \mathrm{Val} \mathrm{BD}$ patients with regard to age of onset $\left(\mathrm{F}_{1,39}=2.8, P=0.11\right)$, length of illnesses $\left(\mathrm{F}_{1,39}=2.0\right.$, $P=0.17)$, medication use $\left(\chi^{2}=0.17, P=0.68\right)$, family history of mood disorders $\left(\chi^{2}<0.01, P=0.97\right)$, number of episodes of the 18 patients who identified a specific number of episodes $\left(\mathrm{F}_{1,15}=0.4, \quad P=0.54\right), \quad$ HAM-D score $\left(\mathrm{F}_{1,38}=0.63, \quad P=0.43\right) \quad$ or YMRS score $\quad\left(\mathrm{F}_{1,39}=1.23\right.$, $P=0.27)$.

\section{Imaging Data}

The interaction between genotype and diagnosis was significant in the analyses of both left and right ACC GM volumes. The differences of the regional ACC GM volumes between $\mathrm{Val} / \mathrm{Val}$ and $\mathrm{Val} / \mathrm{Met}$ subjects were larger for the BD patients compared with the healthy subjects (Talairach and Toronoux coordinates of the voxel of maximum statistical significance; left ACC, $x=-7, y=13, z=25$, $t=3.55, k=66, P=0.011$; right ACC, $x=12, y=25, z=23$, $t=3.24, k=133, P=0.013$ ) (Figure 1). Within-group ROI analysis showed that the Val/Met carriers had significantly smaller ACC and DLPFC GM volumes compared with the $\mathrm{Val} / \mathrm{Val}$ subjects in BD patients and healthy groups (Figure 2). The healthy comparison subjects group also showed that the Val/Met subjects had significantly smaller left hippocampus GM volumes compared with the $\mathrm{Val} / \mathrm{Val}$ subjects (Figure 2). To assess the potential impact of race/ ethnic group on our results, we performed a 3-way ANOVA including factors representing genotype, diagnostic group, and race/ethnic group (coded white and non-white). The three-way interaction was not statistically significant for left or right ACC $\left(\mathrm{F}_{1,76}=1.15, P=0.29 ; \mathrm{F}_{1,76}=1.16, P=0.69\right.$, respectively), but the diagnosis by genotype interaction remained significant for both left and right ACC $\left(\mathrm{F}_{1,76}=5.69, P=0.02 ; \mathrm{F}_{1,76}=5.03, P=0.03\right.$, respectively). This result suggests that the interaction between BDNF genotype and diagnostic group was not moderated by race/ ethnic group.

\section{CVLT Performance}

Figure 3 illustrates that the Val/Met BD showed the poorest performance on the CVLT compared to the Val/Val BD patients and the healthy subjects. There was a significant main effect for diagnosis $\left(F_{1,69}=4.39, P=0.04\right)$, but not for genotype $\left(F_{1,69}=0.82, P=0.63\right)$ or for the interaction between diagnosis and genotype $\left(\mathrm{F}_{4.1,283.3}=0.86, P=0.48\right)$. We conducted exploratory Pearson correlation analyses with Bonferroni correction to examine the association between the CVLT data and the regional GM volumes of

Table I Demographic and Clinical Characteristics of Participants

\begin{tabular}{|c|c|c|c|c|c|}
\hline & \multicolumn{2}{|c|}{ Patients with BD } & \multicolumn{2}{|c|}{ Healthy subjects } & \multirow{2}{*}{$\begin{array}{r}P \text {-value } \\
0.37\end{array}$} \\
\hline & $\mathrm{Val} / \mathrm{Val}(n=24)$ & Val/Met $(n=18)$ & Val/Val $(n=29)$ & Val/Met $(n=13)$ & \\
\hline Female, numbers (\%) & $19(79.1)$ & $14(77.8)$ & $19(65.5)$ & $8(6 \mid .5)$ & 0.53 \\
\hline Years of education, mean (SD) & |4.| (2.2) & | $3.8(2.2)$ & $16.6(3.1)$ & I $6.0(2.9)$ & $<0.01$ \\
\hline Handedness, right numbers (\%) & $23(95.8)$ & $17(94.4)$ & $26(89.7)$ & $12(92.3)$ & 0.35 \\
\hline Ethnicity, Caucasian numbers (\%) & $13(54.2)$ & $10(55.6)$ & $9(31.0)$ & $6(46.2)$ & 0.26 \\
\hline Age of onset, mean (SD), years & |5.| (4.8) & | $8.5(8.6)$ & NA & NA & 0.11 \\
\hline Illness duration, mean (SD), years & $19.9(10.8)$ & $16.2(\mid 1.1)$ & NA & NA & 0.17 \\
\hline HAM-D, mean (SD) & I5.3 (9.4) & I3.4 (9.4) & NA & NA & 0.43 \\
\hline
\end{tabular}

HAM-D, Hamilton Depression Rating Scale; TONI, Test of Nonverbal Intelligence III; WTAR, Wechsler Test of Adult Reading; YMRS, Young Mania Rating Scale. 

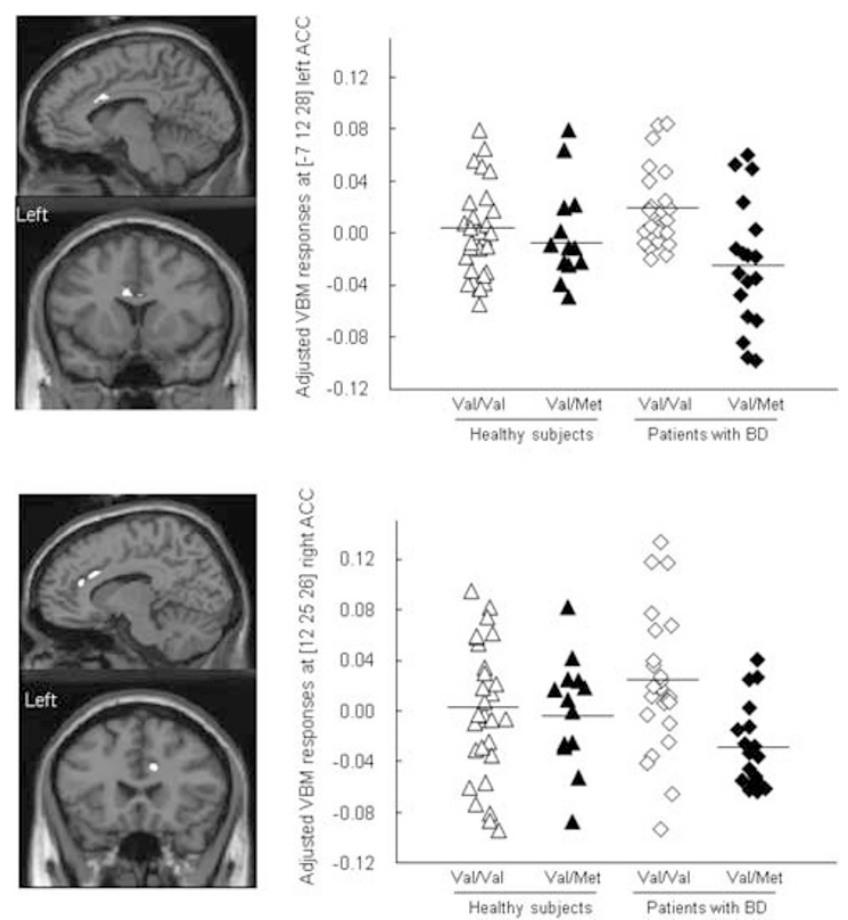

Figure I Scatterplots show the adjusted VBM responses of left and right ACC as a function of BDNF genotype and diagnosis at the Talairach coordinates. These regions showed an interaction between genotype and diagnosis, and the regional ACC GM volume differences between Val/Met and $\mathrm{Val} / \mathrm{Val}$ subjects were larger for the $\mathrm{BD}$ patients compared to the healthy subjects. Horizontal lines represent the mean adjusted VBM response of each group. The $\mathrm{TI}$-weighted template image showed the voxels with statistical significance for left and right ACC. The statistical thresholds showed were the extent thresholds $=50$ voxels and $P_{\text {uncorrected }}$ $<0.005$ for the ROI analysis.

left and right ACC that showed the interaction between genotype and diagnosis in the $\mathrm{Val} / \mathrm{Val}$, the $\mathrm{Val} / \mathrm{Met}$, the $\mathrm{BD}$, and the healthy subjects, respectively. No significant correlations were observed in any group (adjusted $P s>0.1$ ).

\section{DISCUSSION}

We found an association between the BDNF Val66Met polymorphism and GM volumes in the ACC and DLPFC, brain regions, which have been linked in other studies to the pathogenesis of BD. The Val/Met carriers had smaller ACC GM volumes compared to the $\mathrm{Val} / \mathrm{Val}$ carriers in the $\mathrm{BD}$ patients and the healthy subjects (Figure 2). The difference in size of the regional ACC volumes, between $\mathrm{Val} / \mathrm{Val}$ carriers and Val/Met carriers, was larger in the BD patients than in the healthy subjects (Figure 1). This suggests that, in the context of BD, the BDNF Val/Met genotype may play a heightened role in determining the size of the ACC GM. The Val/Met healthy subjects also had smaller hippocampal volumes than the Val/Val healthy subjects, although this difference was not seen in BD subjects. These results replicate previous reports of smaller structural brain volumes among Met carriers (Egan et al, 2003; Pezawas et al, 2004) and suggest that variation in the expression of the BDNF genotype may play a role in determining structural differences in these brain regions, which are relevant to memory, cognitive function and mood regulation. The variation in this gene may play a more prominent role in brain structure differences in subjects affected with BD.

The ACC contributes to working memory (Callicott et al, 1998; Kondo et al, 2004; Ragozzino and Kesner, 2001) and executive functions including attention, inhibition, and resolution of cognitive conflict in executive processes (Fletcher and Henson, 2001; Luks et al, 2002; Smith and Jonides, 1999). There are strong anatomical and functional connections between the ACC and hippocampus. The ACC connects with the hippocampus, OFC, amygdala, periaqueductal gray, nucleus accumbens, hypothalamus, and anterior insula (Bush et al, 2000). The ACC plays a crucial role, along with hippocampus, in the storage and retrieval of remote spatial memories (Maviel et al, 2004; Teixeira et al, 2006). The BDNF Val66Met polymorphism has been implicated in memory and cognitive functions that are impaired in subjects with mood disorders (Bath and Lee, 2006). Our results may provide evidence that the Val66Met polymorphism may play a critical role in ACC.

Bath and Lee (2006) proposed that the BDNF Val/Met polymorphism, ie, carriers of the Met allele compared to those with $\mathrm{Val} / \mathrm{Val}$ alleles, mediates some processes involved in the brain volume reduction reported in $\mathrm{BD}$ patients, particularly the hippocampus. At the molecular level, the Met substitution alters the intracellular trafficking and the activity-dependent (but not the constitutive) secretion of BDNF (Chen et al, 2004). The implicated processes may impact brain volume through decreased dendritic complexity, fewer neuronal and supporting cells, increased cell death, or decreased neurogenesis during embryological development or over the lifespan (Bath and Lee, 2006). This hypothesis may extend to the present findings and explain the smaller ACC volumes observed in our Val/Met subjects compared with $\mathrm{Val} / \mathrm{Val}$ subjects. However, this does not imply that this genetic variant directly regulates ACC volume reduction. It should be noted that this genetic variation may impact on some other neural circuit affecting the ACC function or regulate some other genes directly relevant to the ACC volume reduction. Nonetheless, the findings of this study suggest that the presence of the BDNF Val66Met genotype predicts smaller volumes of brain structures relevant to working memory and further suggest that variation in this gene may play an even more prominent role in brain structure differences in subjects affected with $\mathrm{BD}$.

We replicated the finding of smaller hippocampal and DLPFC GM volumes among Val/Met subjects compared with the Val/Val healthy subjects (Hariri et al, 2003; Pezawas et al, 2004). Previous studies in animals and humans demonstrate an association between BDNF genotype and hippocampus morphology, function, and neurochemistry. Restricted BDNF mutant mice without BDNF in the dorsal cortex and hippocampus failed to learn a hippocampus-dependent memory task (Gorski et al, 2003). Moreover, knockout mice with reduced BDNF expression in the cortex and hippocampus showed approximately $70 \%$ reduction of $\mathrm{BDNF}$ protein level in the hippocampus accompanied by impairment in hippocampal-dependent learning and long-term potentiation (Monteggia et al, 2004). In humans the Val/Met genotype 

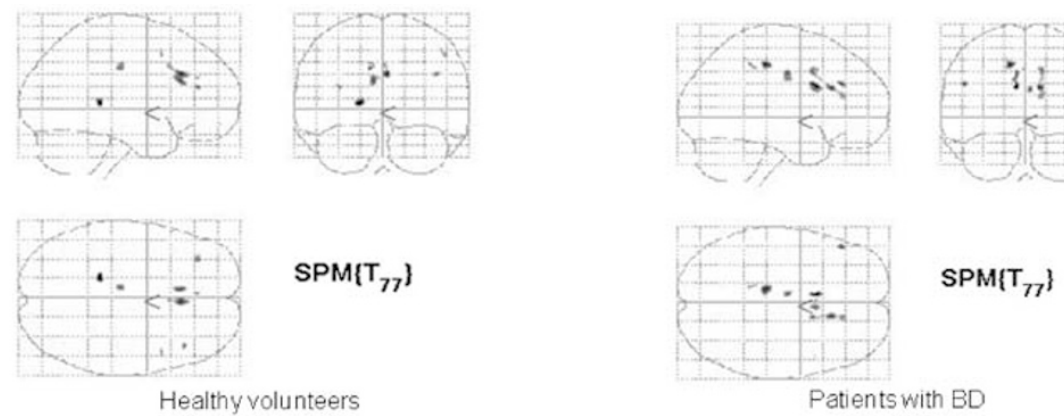

\begin{tabular}{clccc}
\hline & Talairach coordinate & $t$ & $k$ & $p$ \\
\hline Healthy volunteers (Val Nal > Val/Met) & & & & \\
Left DLPFC & $(-33,39,16)$ & 3.06 & 57 & 0.028 \\
Right DLPFC & $(42,29,26)$ & 3.05 & 61 & 0.032 \\
Left ACC & $(-7,25,22)$ & 3.22 & 211 & 0.011 \\
Right ACC & $(3,27,26)$ & 3.34 & 271 & 0.009 \\
Lefthippocampus & $(-18,-36,6)$ & 3.60 & 269 & 0.007 \\
Patients with BD (Val/Nal > Val/Met) & & & & \\
LeftDLPFC & $(-49,33,26)$ & 3.15 & 113 & 0.017 \\
Left ACC & $(-7,13,25)$ & 3.55 & 191 & 0.011 \\
Right ACC & $(12,25,23)$ & 3.12 & 173 & 0.013 \\
\hline
\end{tabular}

'Talairach and Toronoux (1988) coordinates of the voxel of maximal statistical significance

DLPFC Dorsolateral prefrontal cortex. ACC Anterior cingulate cortex

Figure 2 Glass brain maps show the Talairach coordinates that showed significant volume differences between Val/Met and Val/Val groups. The left map represents healthy subjects and the right represents $\mathrm{BD}$ patients. The table under the figure displays the results including $t, k$, and $P$ values.

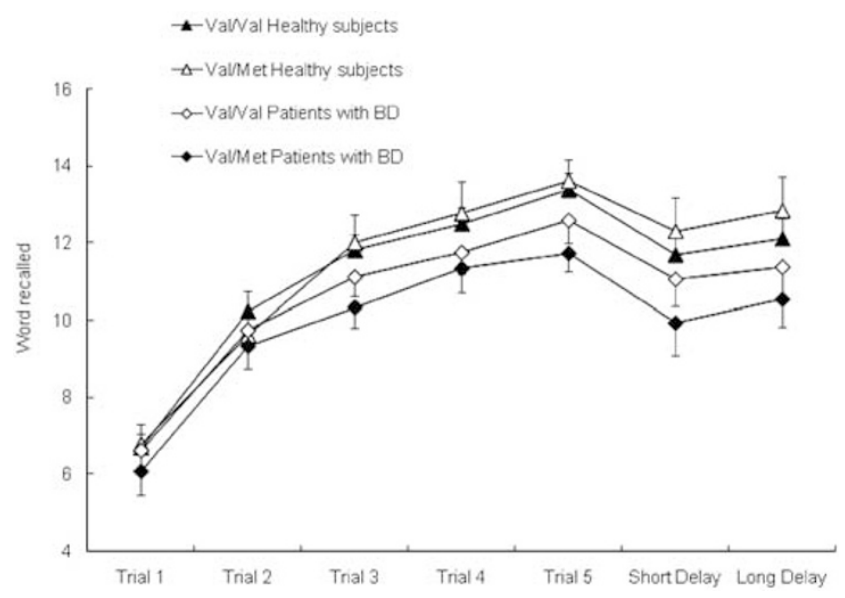

Figure 3 The number of recalled words on the CVLT test for the $\mathrm{BD}$ patients and healthy subjects with $\mathrm{Val} / \mathrm{Met}$ and $\mathrm{Val} / \mathrm{Val}$. Error bars indicate SE.

is associated with poor performance on a hippocampusdependent memory task compared to subjects with the Val/ Val genotype (Egan et al, 2003; Hariri et al, 2003). Furthermore, healthy Val/Met subjects show hippocampal hypoactivation compared with healthy $\mathrm{Val} / \mathrm{Val}$ subjects during a declarative memory (Hariri et al, 2003) and a working memory task (Egan et al, 2003). A magnetic resonance spectroscopy study also demonstrates abnormal neurochemical activity in Val/Met BD patients: Val/Met BD patients show lower creatine + phosphocreatine $(\mathrm{Cr}+\mathrm{PCr})$ levels compared with $\mathrm{Val} / \mathrm{Val} \mathrm{BD}$ patients in the prefrontal cortex involved in the brain circuit of working memory (Frey et al, 2007b).

The current study found no interaction between genotype and diagnosis and no difference between the Val/Met and the $\mathrm{Val} / \mathrm{Val} \mathrm{BD}$ patients with regard to hippocampal volumes. A postmortem study demonstrated reduced pyramidal cell size in the hippocampus of $\mathrm{BD}$ patients compared with healthy control subjects (Liu et al, 2007). Most previous in vivo studies also showed no difference in hippocampal volumes between BD patients and healthy subjects (Frey et al, 2007a), although a few studies have shown smaller hippocampal volumes in BD patients (Bearden et al, 2007; Frazier et al, 2005). Lithium and valproate, primary mood stabilizers for the pharmacological treatment of BD patients, increase BDNF concentration in the rat hippocampus (Frey et al, 2006). Furthermore, psychiatric patients treated with antidepressants at the time of death showed higher hippocampal BDNF expression compared to those not treated with antidepressants (Chen et al, 2001). Antidepressant administration increases BDNF mRNA in the hippocampus (Nibuya et al, 1995) and acutely increases BDNF receptor (Trk B) signaling in the cerebral cortex (Saarelainen et al, 2003). Concerning the effects of antidepressant use on brain volume change, antidepressants increase the proliferation of hippocampal cells, and these new cells mature and become neurons (Malberg et al, 2000). Lithium administration for 4 weeks also increases the whole brain gray matter volume in $\mathrm{BD}$ patients (Moore et al, 2000). Sixty-nine percent of our BD sample were taking antidepressants and/or mood stabilizers at the time of the study. The potential compensatory effects of these 
medications on hippocampal volume size may in part explain why the differences in hippocampal volumes between the $\mathrm{BD}$ patients and healthy subjects did not reach statistical significance. It may also explain why differences between $\mathrm{Val} / \mathrm{Met}$ and $\mathrm{Val} / \mathrm{Val}$ carriers in hippocampal volume were not observed. We did show evidence that the Val/Met genotype influences hippocampal volume in the healthy control sample, where healthy subjects with a Val/ Met genotype had smaller hippocampal volume than healthy $\mathrm{Val} / \mathrm{Val}$ carriers.

The CVLT performance of the BD patients was worse than that of the healthy subjects, as we had previously reported (Bearden et al, 2006), but that of the Val/Met subjects was similar to that of the $\mathrm{Val} / \mathrm{Val}$ subjects in the $\mathrm{BD}$ and the healthy subjects, respectively. The difference between BD and healthy subjects is consistent with prior studies (Bearden et al, 2006; Clark et al, 2002; van Gorp et al, 1998), and the results suggesting no difference between the genotypes also support a recent report on CVLT (Egan et al, 2003). However, the performance of $\mathrm{Val} / \mathrm{Met} \mathrm{BD}$ patients on the Wisconson Card Sorting Test reportedly is inferior to that of $\mathrm{Val} / \mathrm{Val} \mathrm{BD}$ patients (Rybakowski et al, 2003; Rybakowski et al, 2006). The Wisconsin Card Sorting Test measures working memory and executive functions involving frontal cortex, whereas the CVLT assesses complex cognitive processes and declarative memory involving the hippocampus and frontal regions. A recent study also reports an association between CVLT performance and the catechol-O-methyl transferase rs165599 genotype in BD patients (Burdick et al, 2007). Although the CVLT is associated with hippocampal volume (Banos et al, 2004; Tischler et al, 2006) and frontal function (Baldo et al, 2002), the relationship between ACC function and memory processing measured by CLVT is unclear. Therefore, other neurocognitive tasks that activate ACC function (Gehring and Willoughby, 2002; Matsuo et al, 2007) are warranted to determine whether the BDNFVal66Met polymorphism participates in working memory processing related to ACC function in BD patients.

Some methodological limitations of the present study should be noted. As the association between the BDNF Val66Met polymorphism and memory has been observed in schizophrenia, MDD, and neurodegenerative diseases, the finding of this study may not be specific to BD. Studies of patients with schizophrenia showed that Met carriers have poorer spatial and verbal memory performance (Egan et al, 2003; Ho et al, 2006) and smaller hippocampal (Egan et al, 2003; Szeszko et al, 2005), parahippocampal and supramarginal gyrus volumes, which modulate visuo-motor control (Ho et al, 2006), than Val/Val carriers. Met carriers with MDD (Frodl et al, 2007) also have smaller hippocampal volumes compared with $\mathrm{Val} / \mathrm{Val}$ carriers. As the sample size was relatively small for a genetic analysis, this may be the reason for the lack of association between BDNF polymorphism and hippocampal volumes in BD patients. Next, the interpretation of the interaction between the BDNF polymorphism and brain volumes may be modest as the sample is affected by some potentially confounding factors such as medication, ethnicity, and subtype of bipolar disorder. As noted above, antidepressants and mood stabilizers may alter brain volumes in $\mathrm{BD}$ (Malberg et al, 2000). These factors make it difficult to attribute observed brain volume differences between $\mathrm{BD}$ and healthy subjects specifically to the Val66Met polymorphism. The ethnicity is mixed in this study. Stratification of ethnicity is crucial for genetic studies. The samples in this study were not ideally matched with respect to ethnic/racial background although the interaction between the BDNF genotype and the diagnostic group was not moderated by race/ethnic group. Stratification by ethnicity is crucial for genetic studies. The prior studies of the BDNF polymorphism with BD patients demonstrated that Caucasians showed significant associations between Val66Met polymorphism and BD (NevesPereira et al, 2002; Sklar et al, 2002) but Asians did not (Hong et al, 2003; Kunugi et al, 2004; Nakata et al, 2003). Studies with substantial number of ethnically homogeneous subjects would be required to confirm that the main results of this study still exist. Other genes such as 5HTTLPR (Frodl et al, 2004; Hickie et al, 2007; Taylor et al, 2005) and DISC1 Ser704Cys polymorphism (Hashimoto et al, 2006) may potentially mediate the association between the Val66Met polymorphism and brain structural change in patients with mood disorders, and these polymorphisms were not analyzed in this study. As in any association study involving genotypes, undetected population stratification between 'cases' and 'controls' (in this study, between Val/Met carriers and Val/Val carriers) can lead to false positive or negative results. Our control markers, however, suggest that the $\mathrm{Val} / \mathrm{Met}$ and $\mathrm{Val} / \mathrm{Val}$ carriers are reasonably matched, as only one of the 18 control markers showed a statistical difference in genotypes between the Val/Met and Val/Val group, about what one would find by chance in two properly matched genetic samples. Regarding BD subtype, the results of this study may be confounded although there was no significant difference in ACC volumes between bipolar I and II patients and little evidence for a neurobiological difference between bipolar I and II has been reported (McGrath et al, 2004). Then, we did not evaluate the personality or character traits of the participants. Serum BDNF levels are inversely correlated with neuroticism and directly correlated with conscientiousness in mentally healthy individuals (Lang et al, 2004); however, recent studies did not find any association between BDNF Val66Met polymorphism and personality traits, as assessed by the Temperament and Character Inventory, in female healthy subjects (Rybakowski et al, 2007; Tsai et al, 2004). Personality differences between BD and healthy individuals may confound the results of this study. Additional studies are needed to determine if BDNF serum levels are correlated with the BDNF gene-related brain volume differences. Finally, the distribution of the Val/Val $v s$ the Val/Met genotype was not significantly different between the $\mathrm{BD}$ and healthy subjects. Some association studies showed that BD patients have the Val allele at significantly higher frequencies compared with healthy subjects (Lohoff et al, 2005; Tang et al, 2008). The equal distribution in this study may be due to the sample size. Our sample included 42 healthy and $42 \mathrm{BD}$ subjects whereas some previous studies used much larger samples (eg, $375 \mathrm{BD}$ and 208 healthy subjects (Tang et al, 2008) and $621 \mathrm{BD}$ and 998 healthy subjects (Lohoff et al, 2005)). The subjects analyzed in this study were completers for the MRI, neuropsychological and blood tests protocols, and some subjects dropped out. Therefore, the gene distribution of our sample may have some bias due to subject attrition. 
In summary, we examined the relationship between BDNF Val66Met polymorphism and brain volume differences between $\mathrm{BD}$ and healthy individuals. We report the novel finding that the Val/Met carriers showed smaller ACC GM volumes compared to the Val/Val carriers and that this genotype-based difference was larger in the BD patients than in the healthy control subjects.

\section{ACKNOWLEDGEMENTS}

This study was partly supported by MH 68766, MH 068662 , RR 20571, UTHSCSA GCRC (M01-RR-01346), NARSAD, Veterans Administration (Merit Review), and the Krus Endowed Chair in Psychiatry (UTHSCSA). We thank Dr Hidenori Yamasue (University of Tokyo), Dr Jorge Almeida (University of Pittsburgh), and Dr Kiyotaka Nemoto (University of Tsukuba) for providing assistance with the VBM protocol.

\section{DISCLOSURE/CONFLICT OF INTEREST}

Emel S Monkul serves as a consultant for Eli Lilly, Brazil. The other authors declare that they do not have any commercial or financial involvements that might present an appearance of a conflict of interest in connection with the submitted article.

\section{REFERENCES}

Baldo JV, Delis D, Kramer J, Shimamura AP (2002). Memory performance on the California Verbal Learning Test-II: findings from patients with focal frontal lesions. J Int Neuropsychol Soc 8: 539-546.

Banos JH, Roth DL, Palmer C, Morawetz R, Knowlton R, Faught E et al (2004). Confirmatory factor analysis of the California verbal learning test in patients with epilepsy: relationship to clinical and neuropathological markers of temporal lobe epilepsy. Neuropsychology 18: 60-68.

Bath KG, Lee FS (2006). Variant BDNF (Val66Met) impact on brain structure and function. Cogn Affect Behav Neurosci 6: 79-85.

Bearden CE, Glahn DC, Monkul ES, Barrett J, Najt P, Villarreal V et al (2006). Patterns of memory impairment in bipolar disorder and unipolar major depression. Psychiatry Res 142: 139-150.

Bearden CE, Thompson PM, Dalwani M, Hayashi KM, Lee AD, Nicoletti $M$ et al (2007). Greater cortical gray matter density in lithium-treated patients with bipolar disorder. Biol Psychiatry 62: 7-16.

Brown L, Sherbenou R, Johhnsen S (1997). Test of Nonverbal Intelligence III: A Language-free Measure of Cognitive Ability. Pro-ED: Austin, TX.

Bueller JA, Aftab M, Sen S, Gomez-Hassan D, Burmeister M, Zubieta JK (2006). BDNF Val66Met allele is associated with reduced hippocampal volume in healthy subjects. Biol Psychiatry 59: $812-815$.

Burdick KE, Funke B, Goldberg JF, Bates JA, Jaeger J, Kucherlapati $\mathrm{R}$ et al (2007). COMT genotype increases risk for bipolar I disorder and influences neurocognitive performance. Bipolar Disord 9: 370-376.

Bush G, Luu P, Posner MI (2000). Cognitive and emotional influences in anterior cingulate cortex. Trends Cogn Sci 4: 215-222.

Callicott JH, Ramsey NF, Tallent K, Bertolino A, Knable MB, Coppola $\mathrm{R}$ et al (1998). Functional magnetic resonance imaging brain mapping in psychiatry: methodological issues illustrated in a study of working memory in schizophrenia. Neuropsychopharmacol 18: 186-196.

Chen B, Dowlatshahi D, MacQueen GM, Wang JF, Young LT (2001). Increased hippocampal BDNF immunoreactivity in subjects treated with antidepressant medication. Biol Psychiatry 50: $260-265$.

Chen ZY, Patel PD, Sant G, Meng CX, Teng KK, Hempstead BL et al (2004). Variant brain-derived neurotrophic factor (BDNF) (Met66) alters the intracellular trafficking and activity-dependent secretion of wild-type BDNF in neurosecretory cells and cortical neurons. J Neurosci 24: 4401-4411.

Clark L, Iversen SD, Goodwin GM (2002). Sustained attention deficit in bipolar disorder. Br J Psychiatry 180: 313-319.

Cunha AB, Frey BN, Andreazza AC, Goi JD, Rosa AR, Goncalves CA et al (2006). Serum brain-derived neurotrophic factor is decreased in bipolar disorder during depressive and manic episodes. Neurosci Lett 398: 215-219.

Delis D, Kramer J, Kaplan E, Ober B (2000). California Verbal Learning Test (CVLT-II) Manual. Harcourt Assessment Company: San Antonio.

Egan MF, Kojima M, Callicott JH, Goldberg TE, Kolachana BS, Bertolino A et al (2003). The BDNF val66met polymorphism affects activity-dependent secretion of BDNF and human memory and hippocampal function. Cell 112: 257-269.

First MB, Spitzer RL, Gibbon M, Janet W (1996a). Structured Clinical Interview for DSM-IV Axis I Disorders- Non- Patient Edition. Biometrics Research Department, New York State Psychiatric Institute: New York.

First MB, Spitzer RL, Gibbon M, Williams JBW (1996b). Structured Clinical Interview for DSM-IV Axis I Disorders, Research Version, Patient Edition. Biometrics Research Department, New York State Psychiatric Institute: New York.

Fletcher PC, Henson RN (2001). Frontal lobes and human memory: insights from functional neuroimaging. Brain 124: 849-881.

Frazier JA, Chiu S, Breeze JL, Makris N, Lange N, Kennedy DN et al (2005). Structural brain magnetic resonance imaging of limbic and thalamic volumes in pediatric bipolar disorder. $\mathrm{Am}$ J Psychiatry 162: 1256-1265.

Frey BN, Andreazza AC, Cereser KM, Martins MR, Valvassori SS, Reus GZ et al (2006). Effects of mood stabilizers on hippocampus BDNF levels in an animal model of mania. Life Sci 79: 281-286.

Frey BN, Andreazza AC, Nery FG, Martins MR, Quevedo J, Soares JC et al (2007a). The role of hippocampus in the pathophysiology of bipolar disorder. Behav Pharmacol 18: 419-430.

Frey BN, Walss-Bass C, Stanley JA, Nery FG, Matsuo K, Nicoletti MA et al (2007b). Brain-derived neurotrophic factor val66met polymorphism affects prefrontal energy metabolism in bipolar disorder. Neuroreport 18: 1567-1570.

Frodl T, Meisenzahl EM, Zill P, Baghai T, Rujescu D, Leinsinger G et al (2004). Reduced hippocampal volumes associated with the long variant of the serotonin transporter polymorphism in major depression. Arch Gen Psychiatry 61: 177-183.

Frodl T, Schule C, Schmitt G, Born C, Baghai T, Zill P et al (2007). Association of the brain-derived neurotrophic factor Val66Met polymorphism with reduced hippocampal volumes in major depression. Arch Gen Psychiatry 64: 410-416.

Gehring WJ, Willoughby AR (2002). The medial frontal cortex and the rapid processing of monetary gains and losses. Science 295: 2279-2282.

Good CD, Johnsrude IS, Ashburner J, Henson RN, Friston KJ, Frackowiak RS (2001). A voxel-based morphometric study of ageing in 465 normal adult human brains. NeuroImage 14: 21-36.

Gorski JA, Balogh SA, Wehner JM, Jones KR (2003). Learning deficits in forebrain-restricted brain-derived neurotrophic factor mutant mice. Neuroscience 121: 341-354. 
Gratacos M, Gonzalez JR, Mercader JM, de Cid R, Urretavizcaya M, Estivill X (2007). Brain-derived neurotrophic factor Val66Met and psychiatric disorders: meta-analysis of case-control studies confirm association to substance-related disorders, eating disorders, and schizophrenia. Biol Psychiatry 61: 911-922.

Green EK, Raybould R, Macgregor S, Hyde S, Young AH, O'Donovan MC et al (2006). Genetic variation of brain-derived neurotrophic factor (BDNF) in bipolar disorder: case-control study of over 3000 individuals from the UK. Br J Psychiatry 188: 21-25.

Hamilton M (1960). A rating scale for depression. J Neurol Neurosurg Psychiatry 23: 56-62.

Hariri AR, Goldberg TE, Mattay VS, Kolachana BS, Callicott JH, Egan MF et al (2003). Brain-derived neurotrophic factor val66met polymorphism affects human memory-related hippocampal activity and predicts memory performance. $J$ Neurosci 23: 6690-6694.

Hashimoto R, Numakawa T, Ohnishi T, Kumamaru E, Yagasaki Y, Ishimoto $\mathrm{T}$ et al (2006). Impact of the DISC1 Ser704Cys polymorphism on risk for major depression, brain morphology and ERK signaling. Hum Mol Genet 15: 3024-3033.

Hickie IB, Naismith SL, Ward PB, Scott EM, Mitchell PB, Schofield PR et al (2007). Serotonin transporter gene status predicts caudate nucleus but not amygdala or hippocampal volumes in older persons with major depression. J Affect Disord 98: 137-142.

Ho BC, Milev P, O'Leary DS, Librant A, Andreasen NC, Wassink TH (2006). Cognitive and magnetic resonance imaging brain morphometric correlates of brain-derived neurotrophic factor Val66Met gene polymorphism in patients with schizophrenia and healthy volunteers. Arch Gen Psychiatry 63: 731-740.

Holnack J (2001). Wechsler Test of Adult Reading.. The Psychological Corporation: San Antonio, TX.

Hong CJ, Huo SJ, Yen FC, Tung CL, Pan GM, Tsai SJ (2003). Association study of a brain-derived neurotrophic-factor genetic polymorphism and mood disorders, age of onset and suicidal behavior. Neuropsychobiol 48: 186-189.

Huang EJ, Reichardt LF (2001). Neurotrophins: roles in neuronal development and function. Annu Rev Neurosci 24: 677-736.

Kanazawa T, Glatt SJ, Kia-Keating B, Yoneda H, Tsuang MT (2007). Meta-analysis reveals no association of the Val66Met polymorphism of brain-derived neurotrophic factor with either schizophrenia or bipolar disorder. Psychiatr Genet 17: 165-170.

Karege F, Schwald M, El Kouaissi R (2004). Drug-induced decrease of protein kinase a activity reveals alteration in BDNF expression of bipolar affective disorder. Neuropsychopharmacol 29: 805-812.

Kondo H, Morishita M, Osaka N, Osaka M, Fukuyama H, Shibasaki $\mathrm{H}$ (2004). Functional roles of the cingulo-frontal network in performance on working memory. NeuroImage 21: 2-14.

Kunugi H, Iijima Y, Tatsumi M, Yoshida M, Hashimoto R, Kato T et al (2004). No association between the Val66Met polymorphism of the brain-derived neurotrophic factor gene and bipolar disorder in a Japanese population: a multicenter study. Biol Psychiatry 56: 376-378.

Lancaster JL, Woldorff MG, Parsons LM, Liotti M, Freitas CS, Rainey L et al (2000). Automated Talairach atlas labels for functional brain mapping. Hum Brain Mapp 10: 120-131.

Lang UE, Hellweg R, Gallinat J (2004). BDNF serum concentrations in healthy volunteers are associated with depression-related personality traits. Neuropsychopharmacol 29: 795-798.

Lang UE, Hellweg R, Seifert F, Schubert F, Gallinat J (2007). Correlation between serum brain-derived neurotrophic factor level and an in vivo marker of cortical integrity. Biol Psychiatry 62: $530-535$.

Liu L, Schulz SC, Lee S, Reutiman TJ, Fatemi SH (2007). Hippocampal CA1 pyramidal cell size is reduced in bipolar disorder. Cell Mol Neurobiol 27: 351-358.
Lohoff FW, Sander T, Ferraro TN, Dahl JP, Gallinat J, Berrettini WH (2005). Confirmation of association between the Val66Met polymorphism in the brain-derived neurotrophic factor (BDNF) gene and bipolar I disorder. Am J Med Genet B Neuropsychiatr Genet 139: 51-53.

Luks TL, Simpson GV, Feiwell RJ, Miller WL (2002). Evidence for anterior cingulate cortex involvement in monitoring preparatory attentional set. NeuroImage 17: 792-802.

Machado-Vieira R, Dietrich MO, Leke R, Cereser VH, Zanatto V, Kapczinski F et al (2007). Decreased plasma brain derived neurotrophic factor levels in unmedicated bipolar patients during manic episode. Biol Psychiatry 61: 142-144.

Malberg JE, Eisch AJ, Nestler EJ, Duman RS (2000). Chronic antidepressant treatment increases neurogenesis in adult rat hippocampus. J Neurosci 20: 9104-9110.

Maldjian JA, Laurienti PJ, Burdette JH (2004). Precentral gyrus discrepancy in electronic versions of the Talairach atlas. NeuroImage 21: 450-455.

Maldjian JA, Laurienti PJ, Kraft RA, Burdette JH (2003). An automated method for neuroanatomic and cytoarchitectonic atlas-based interrogation of fMRI data sets. NeuroImage 19: 1233-1239.

Matsuo K, Glahn DC, Peluso MA, Hatch JP, Monkul ES, Najt P et al (2007). Prefrontal hyperactivation during working memory task in untreated individuals with major depressive disorder. Mol Psychiatry 12: 158-166.

Maviel T, Durkin TP, Menzaghi F, Bontempi B (2004). Sites of neocortical reorganization critical for remote spatial memory. Science 305: 96-99.

McGrath BM, Wessels PH, Bell EC, Ulrich M, Silverstone PH (2004). Neurobiological findings in bipolar II disorder compared with findings in bipolar I disorder. Can J Psychiatry 49: 794-801.

McIntosh AM, Moorhead TW, McKirdy J, Sussmann JE, Hall J, Johnstone EC et al (2007). Temporal grey matter reductions in bipolar disorder are associated with the BDNF Val66Met polymorphism. Mol Psychiatry 12: 902-903.

Monteggia LM, Barrot M, Powell CM, Berton O, Galanis V, Gemelli $\mathrm{T}$ et al (2004). Essential role of brain-derived neurotrophic factor in adult hippocampal function. Proc Natl Acad Sci USA 101: 10827-10832.

Moore GJ, Bebchuk JM, Wilds IB, Chen G, Manji HK (2000). Lithium-induced increase in human brain grey matter. Lancet 356: $1241-1242$.

Muller MB, Toschi N, Kresse AE, Post A, Keck ME (2000). Longterm repetitive transcranial magnetic stimulation increases the expression of brain-derived neurotrophic factor and cholecystokinin mRNA, but not neuropeptide tyrosine mRNA in specific areas of rat brain. Neuropsychopharmacol 23: 205-215.

Nakata K, Ujike H, Sakai A, Uchida N, Nomura A, Imamura T et al (2003). Association study of the brain-derived neurotrophic factor (BDNF) gene with bipolar disorder. Neurosci Lett 337: 17-20.

Nemoto K, Ohnishi T, Mori T, Moriguchi Y, Hashimoto R, Asada T et al (2006). The Val66Met polymorphism of the brain-derived neurotrophic factor gene affects age-related brain morphology. Neurosci Lett 397: 25-29.

Neves-Pereira M, Mundo E, Muglia P, King N, Macciardi F, Kennedy JL (2002). The brain-derived neurotrophic factor gene confers susceptibility to bipolar disorder: evidence from a family-based association study. Am J Hum Genet 71: 651-655.

Nibuya M, Morinobu S, Duman RS (1995). Regulation of BDNF and trkB mRNA in rat brain by chronic electroconvulsive seizure and antidepressant drug treatments. J Neurosci 15: 7539-7547.

Oldfield RC (1971). The assessment and analysis of handedness: the Edinburgh inventory. Neuropsychologia 9: 97-113.

Pezawas L, Verchinski BA, Mattay VS, Callicott JH, Kolachana BS, Straub RE et al (2004). The brain-derived neurotrophic factor 
val66met polymorphism and variation in human cortical morphology. J Neurosci 24: 10099-10102.

Ragozzino ME, Kesner RP (2001). The role of rat dorsomedial prefrontal cortex in working memory for egocentric responses. Neurosci Lett 308: 145-148.

Russo-Neustadt A, Beard RC, Cotman CW (1999). Exercise, antidepressant medications, and enhanced brain derived neurotrophic factor expression. Neuropsychopharmacol 21: 679-682.

Rybakowski F, Dmitrzak-Weglarz M, Szczepankiewicz A, Skibinska M, Slopien A, Rajewski A et al (2007). Brain derived neurotrophic factor gene Val66Met and -270C/T polymorphisms and personality traits predisposing to anorexia nervosa. Neuro Endocrinol Lett 28: 153-158.

Rybakowski JK, Borkowska A, Czerski PM, Skibinska M, Hauser J (2003). Polymorphism of the brain-derived neurotrophic factor gene and performance on a cognitive prefrontal test in bipolar patients. Bipolar Disord 5: 468-472.

Rybakowski JK, Borkowska A, Skibinska M, Hauser J (2006). Illness-specific association of val66met BDNF polymorphism with performance on Wisconsin Card Sorting Test in bipolar mood disorder. Mol Psychiatry 11: 122-124.

Saarelainen T, Hendolin P, Lucas G, Koponen E, Sairanen M, MacDonald E et al (2003). Activation of the TrkB neurotrophin receptor is induced by antidepressant drugs and is required for antidepressant-induced behavioral effects. J Neurosci 23: 349-357.

Shimizu E, Hashimoto K, Okamura N, Koike K, Komatsu N, Kumakiri $C$ et al (2003). Alterations of serum levels of brainderived neurotrophic factor (BDNF) in depressed patients with or without antidepressants. Biol Psychiatry 54: 70-75.

Sklar P, Gabriel SB, McInnis MG, Bennett P, Lim YM, Tsan G et al (2002). Family-based association study of 76 candidate genes in bipolar disorder: BDNF is a potential risk locus. Brain-derived neutrophic factor. Mol Psychiatry 7: 579-593.

Smith EE, Jonides J (1999). Storage and executive processes in the frontal lobes. Science 283: 1657-1661.

Soares JC, Mann JJ (1997). The functional neuroanatomy of mood disorders. J Psychiatr Res 31: 393-432.

Sowell ER, Peterson BS, Thompson PM, Welcome SE, Henkenius AL, Toga AW (2003). Mapping cortical change across the human life span. Nat Neurosci 6: 309-315.
Szeszko PR, Lipsky R, Mentschel C, Robinson D, Gunduz-Bruce H, Sevy S et al (2005). Brain-derived neurotrophic factor val66met polymorphism and volume of the hippocampal formation. $\mathrm{Mol}$ Psychiatry 10: 631-636.

Tang J, Xiao L, Shu C, Wang G, Liu Z, Wang X et al (2008). Association of the brain-derived neurotrophic factor gene and bipolar disorder with early age of onset in mainland China. Neurosci Lett 433: 98-102.

Taylor WD, Steffens DC, Payne ME, MacFall JR, Marchuk DA, Svenson IK et al (2005). Influence of serotonin transporter promoter region polymorphisms on hippocampal volumes in late-life depression. Arch Gen Psychiatry 62: 537-544.

Teixeira CM, Pomedli SR, Maei HR, Kee N, Frankland PW (2006). Involvement of the anterior cingulate cortex in the expression of remote spatial memory. J Neurosci 26: 7555-7564.

Tischler L, Brand SR, Stavitsky K, Labinsky E, Newmark R, Grossman $\mathrm{R}$ et al (2006). The relationship between hippocampal volume and declarative memory in a population of combat veterans with and without PTSD. Ann NY Acad Sci 1071: 405-409.

Tsai SJ, Hong CJ, Yu YW, Chen TJ (2004). Association study of a brain-derived neurotrophic factor (BDNF) Val66Met polymorphism and personality trait and intelligence in healthy young females. Neuropsychobiol 49: 13-16.

Tzourio-Mazoyer N, Landeau B, Papathanassiou D, Crivello F, Etard O, Delcroix N et al (2002). Automated anatomical labeling of activations in SPM using a macroscopic anatomical parcellation of the MNI MRI single-subject brain. NeuroImage 15: 273-289.

van Gorp WG, Altshuler L, Theberge DC, Wilkins J, Dixon W (1998). Cognitive impairment in euthymic bipolar patients with and without prior alcohol dependence. A preliminary study. Arch Gen Psychiatry 55: 41-46.

Vigers AJ, Baquet ZC, Jones KR (2000). Expression of neurotrophin-3 in the mouse forebrain: insights from a targeted LacZ reporter. J Comp Neurol 416: 398-415.

Yan Q, Radeke MJ, Matheson CR, Talvenheimo J, Welcher AA, Feinstein SC (1997). Immunocytochemical localization of TrkB in the central nervous system of the adult rat. J Comp Neurol 378: $135-157$.

Young RC, Biggs JT, Ziegler VE, Meyer DA (1978). A rating scale for mania: reliability, validity and sensitivity. Br J Psychiatry 133: $429-435$. 